\title{
Facility Layout Decision Model for Small and Medium Shopping Mall
}

\author{
Ahasanul Haque" \\ Syeada Irfath Jahan \\ Naila Anwar Chowdhurys \\ Md Atiqur Rahman Sarker \\ Department of Business Administration ${ }^{1234}$ \\ International Islamic University Malaysia (IIUM), Malaysia' ${ }^{1234}$
}

\begin{abstract}
This study is based on a case analysis where a particular medium size shopping mall has been taken for observation. Field work has been utilized as the ground for suggesting a new model for a shopping mall layout. Various factors necessitated the undertaking of this particular study. First and foremost, many methods prevail in business research, but they are hardly understood by practitioners due to the inclusion of advanced mathematical techniques. Secondly, for the purpose of suggesting a new shopping mall layout, this study has taken into account a number of vital factors which were not previously considered in any earlier methods. The significance of retail trading in small and medium size shopping malls has been confirmed through many reports available in contemporary literature. Therefore, today's highly competitive retail industry demands a well-designed facility layout to protect the interest of both traders as well as customers. In light of this view, the current research analyzed a real facility layout of a medium shopping mall to ensure the effectiveness as well as flexibility of its implementation.
\end{abstract}

Keywords: Facility Layout Decision Model, Retail, Industry, Small and Medium Shopping Malls

\footnotetext{
*Corresponding Author: Ahasanul Haque, Email: ahasanul@iium.edu.my DOI: https://doi.org/10.37227/ITHJ-2021-02-108
}

\section{Introduction}

Growth of shopping mall industry is magnificent all over the world specially, wherever the breeze of urbanization is blowing to develop the standard of living. This upward trend of shopping mall industry encouraged high competition with sensitivity of the audience. In this research, the analysis has been narrowed to small and medium shopping mall so that, average marketplace can prepare precise facility layout design to benefit the buyers as well as the sellers. Many different researches have been conducted on shopping malls, but the findings could not be implemented in real scenario due to the difficulties of being understood by the general audience. The various factors that influence the time visitors are willing to spend in a shopping mall and their shopping behavior have been thoroughly 
analyzed in this study to understand the existing practice for small or medium shopping malls.

Development of the economy fuels transactions that take place in the marketplace, regardless of whether they are in shopping mall or wet markets. Urbanization dictates the transactions in mall environment through inviting tourists and persuading visitors to make unplanned purchases (Debek, 2015). The so called "price reduction" does not work alone in the highly competitive, intense shopping industry. When it comes to shopping destination, modern buyers seek more than price. Nature of product, as usual, plays a big role for visitors to decide if they are willing to shop at a particular shopping outlet (Mowrey et al., 2018). To target the unplanned purchase of visitors, assurance of the right kind of positioning in the mall building is mandatory. Management of small and medium shopping malls ignore these facets which are crucial to sustain themselves in this competitive market for better positioning of the business outlet (Fahmy et al., 2014). That is why this study focusing on facility layout for shopping mall for further accessibility and attractiveness to the customers.

Analysis of trader's perspective regarding promotional offers in multi-storied shopping mall would not be effective without the presence of a well-planned positioning of the mall itself (Pope et al., 2020). Positioning of outlet for the product of regular consumption would not be same as the products for entertainment, transactions, jewelry, food, electronics, kids and household accessories. Therefore, volume of transactions with mark-up practices need to be considered when designing the facility layout decision model. Markup and footfall of customers are vital for gaining an understanding regarding the sensitivity of the business in terms of risk and security needed from the mall management to avoid accidents in the mall layout design (Chotipanich \& Issarasak, 2017). Size of transaction for individual product also needs to come under consideration for assuring healthy facility layout decision model. Some products that are highly sensitive towards customer switching behavior need to be separated or brought at lower level so that, they can be easily purchased by buyers. Thus, it is essential to obtain coordination from mall management as well as attain the traders' warm effort for establishing a successful smallmedium shopping mall.

The usual practice of facility layout is apparent in following the pattern of existing mega malls. This concept fuels the thought of spreading the business rather than taking into account the rational influential factors. There should always be a match between revenue of outlet with its maintenance. Following the pattern of the biggest mall may not always be a profitable strategy for a small and medium shopping mall.

Marketplaces in urban demographic settings attract large number of buyers and sellers, which can be termed as market thickness. Co-existence of many shopping malls along with traditional markets in a marketplace causes market congestion. This problem may be resolved by developing small kiosks for transactions and allowing consumers to indent customized products and services from the base stores (Roth, 2008).

The growth of market share for specialized retailers and large departmental stores depends on the size of consumer segment in a given urban population. It is observed that consumers' buying preferences become more diversified as the extent of retail stores increase within a confined area. Thus, the market size reaches a threshold and the consumers' preferences of shopping are jeopardized due to indecisiveness in shopping

(Gopalakrishnan et al., 2004). 
Small and medium shopping malls require considerable strategic layout to attract the annual tourists' visits as well as meet the needs of local customers (Debek, 2015). For small size transaction practices, these outlet encounter highly sensitive customer who can switch easily to wet market or traditional marketplace. Mall management should strictly observe such matters while designing the floor to facilitate large number of buyers. Pharmacy and medicine shops are another type of business requiring stations or counters at lower floor so that, the need for these urgent products does not require customers to come up all the way to the upper floor.

All over the world investors are investing heavily on shopping malls (Pope et al., 2020). These malls need to be reshaped in terms of facility layout and strategic advancement. Intense competition requires shopping malls to be re-engineered; as the industry is seeking effective attention from large number of buyers. This research has been conducted on a case relating to a small-medium shopping mall, which has been analyzed by each floor design and layout to facilitate businesses as well as the customers.

Upon researching the ins and outs of the mall, this study has recommended a method for estimating the weight for the outlets to fit into the shopping malls that are small and medium in size. This weight has been estimated by considering many factors that are integral for the growing profit maximization requirement of shopping malls. Trade of vast wet markets is now largely transforming into urbanized form of shopping malls. Buyers are visiting the place not only to purchase, rather more as place of entertainment, soothing and refreshment in their busy life. Thus, requirement of facility layout became much necessary in designing the floor to floor planning into small-medium malls in modern competitive industry. More specifically, this research took the initiative of understanding and analyzing the following aspects.

a. To analyze the current practice of facility layout in small-medium shopping malls

b. To identify the most practiced factors to design the modern facility layout by different researches

c. Assessing the gap in facilitation through facility layout decision models' practice

d. Reviewing literature review regarding modern mall practice on facility layout

e. Structuring a new model for facility layout that assures profitability of outlets within shopping malls

f. Discussing the new factors that should be recommended into upcoming research of facility layout

\section{Literature Review}

Facility layout decision is the significant catalyst which facilitates the operational procedure in an effective manner for thriving optimum in a given time period. Irrespective of the nature of the business, production or services, the layout planning has remarkable influence on contributing to the core business interest like cost effectiveness and time efficiency (Can et al., 2016; Chae \& Regan, 2016). The most practiced layout planning study is held on manufacturing industry to reduce the cost of production. However, over the last two decades, the growth of shopping mall has been outstanding all over the world. In this highly competitive retail industry, some shopping malls are quiet successful in 
terms of customer satisfaction, quality of service and efficient stock management for all the businesses who are coexisting together in a particular meeting place for buyer and seller. The size, layout and strategic management of a particular shopping mall has significant effect on consumer behavior and boosting the demand of product in consumer market. Life-style and economy malls have been constantly adapting and changing in both style and substance in order to attract the increasingly sophisticated customer (Behera \& Mishra, 2017). Nowadays, facility layout decision for shopping mall is very competitive and frequently changing as it requires upgrading of service in order to satisfy customers' needs. As a result, the traditional anchor-based shopping malls got the newer version of mall designs including outlet malls and hybrid malls consisting of both open-air and enclosed store shopping (Mowrey et al., 2018), and main street malls basically designed for urban shopping and consumption (Debek, 2015). This is the time to identify the layout decision in a scientific manner by justifying the prioritized factors that affect the time and cost from the standpoint of customers and businesses as well.

In practice of facility layout planning, some remarkable success can be followed to take ahead the recent followers to those who are dealing to improve their facility layout within. Like Trish Martineck, director of health care communication at HKS, Dallas, mentioned in his article about successful facility profile of hospital in the University of Miami, who successfully utilized only 188,000 square foot space and $\$ 27$ million. The degree of success has outperformed as health facility decreased from 22 to 11 days (Martineck, 2002). So, it can be said that regardless of the capital and spaces, it is vital to design the best layout which facilitates both the service provider and receiver. The method or techniques used to solve the complex planning is the closeness rating between departments and qualitative along with quantitative factors. In order to find the weight of this closeness factors, a computer program called FUZZY was invented based on Fuzzy Decision Making System (FDMS). It is actually based on fuzzy set theory which has been introduced by Zadeh (1965) to deal with the vagueness and uncertainties in problems (Kahraman \& Otay, 2019).

Systematic layout planning is one of the traditional techniques applied to the layout problem. Among the upgraded method, which is derived by the computer system, are CRAFT, COFAD, PLANET, CORELA and ALDEP (Suhardi et al., 2019). They are used to optimize planning for the organization's layout. In the field of Operation Management, the experts and academicians mostly used the proposed taxonomy identified by five operational types: project, job shop, batch process, assembly line and continuous flow (Jain \& Yadav, 2017). The taxonomy is derived mainly from the analysis based on two criteria product/ process mix and process life cycle. In case of service like hotel and shopping mall facility, a similar taxonomy has been proposed which identified that service could be categorized according to their degree of labour intensity and level of customization into four types, service shop, service factory, mass service and professional service (Suhradi et al., 2019). In terms of computer aided decision making, each facet of the overall computer based system is described as it pertains to add value in terms of facility design function. Finally, the result obtained from the system are discussed and benefit highlighted, leading to conclusions on the effectiveness of computer based system that ties together the salient aspects of plant layout, material handling and warehousing (Gopalakrishnan et al., 2004). On the basis of the prior discussion, it is to be said that all these methods are mostly being used in the manufacturing and architectural layout decision making, but in terms growing number of shopping mall layout, it is rare to be implemented for. Eventually, social 
motivations predict perception of shopping mall design, variety and excitement as well as consumer's desire to stay and intent to return to the mall.

All these above motivations can be implemented if proper layout decision is made according to prior requirement to provide the best customer facilitation inside the shopping environment. In North American culture, malls had become fixtures in most major markets by the early 1970s (Can et al., 2016). Nowadays, it is to be reconsidering to compete within highly growing industry like shopping mall. In Malaysia, the growth of shopping mall industry after 1997/1998 has been about 20 percent, and the tendency of the citizen to spend more time in shopping malls has increased significantly, but still following the traditional way, developers attracted consumers through the promise of wide assortment of stores and merchandise available in a single location (Ahmed et al., 2007). Maturation of the mall industry has led to the tendency for many malls to closely resemble one another, with many offering comparable products at comparable prices; due to which many malls have lost their individual profile (Debek, 2015). The modern management of all the shopping malls trying to create a competitive advantage can be significantly effective and efficiently sustained when the layout of the mall will be scientifically planned; balancing the interest of both the customer and trader.

The inherent relationship between shop size, tenant type and location have been discussed by Chotipanich \& Issarasak (2017). They have classified the shop into two different categories, first is the non-impulse trade (where consumers visit the shop with planned step for purchase) and secondly, impulse trade (where consumers visit the shop with last minute decision for purchase). In this research, it has been found that more nonimpulse trade is located in high floors of shopping malls as recommended by researchers. Considering machine dimensions and capacity, the optimization process gets forwarded per distance for minimization of cost factors. These two dimensional layouts have been discussed relating to the arrangement of manufacturing facilities for different patterns of operation (Behera \& Mishra, 2017; Zhu et al., 2018). This method relates to establishing new stores into competition that is captured from the market share of the existing stores of similar business. The problem is that competitors may react against new entry in the market or industry. Total accumulation cost, including fixed and transportation cost, has been considered to capture the maximization of total market share.

The distance a consumer is willing to travel is proportional to the size of the shopping mall. This explains the reason for distant travelling to execute shopping than nearest options. Retail location has long been known to be a strategic business decision for several reasons (Can et al., 2016; Fahmy et al., 2014). Firstly, selection of location gets influenced by the accessibility of the outlet as per spatial interaction model. Secondly, retailers will be able to develop a sustainable advantage by selecting precise location. Business performances are significantly relying on the selection of location. Any deviation less than perfect could face failure. In certain industries, relevant and important department should be located to nearby and also differentiate the department that should not be in close circumstances (Pope et al., 2020). Optimization of production is a crucial objective for any business which needs proper planning and scheduling of tasks as well as engagement of workstation. Establishment of efficiency relies upon the placement of production equipment within the plant. This factors also relate between the manufacturing process and the available surface. Proper placement of machinery has been considered repeatedly important towards optimal utilization of available space, time and cost along with flexibility of production. Therefore, any deviation of error in facility layout may cause great loss (Chaem \& Regan, 2016). Apart from this, the influencing factors were tone of a 
particular operation of production lines, workshifts, batch size, transport variation and inventory. Because of possible connection between placement and the resulting deviation, the problem of optimization resolves with one criteria (Chae \& Regan, 2016).

Facility layout is a developed area of business research that identifies the disposition of entities that produce goods as well as services (Suhardi et al., 2019). Facility layout is not a unilateral framed procedure; it presents a wide set of SBO procedure. This method is quite intelligent to design dynamic and robust facility layout for manufacturing operating procedure. A review has been made on Multiple-Attribute Decision Making (MADM) methods in perspective of plant layout design problem, which avails both qualitative and quantitative design criterion (Zeng et al., 2020). Literature review introduces new processes, objectives, solutions, details and evaluates production system with precise facility layout to build an efficient as well as organized process. Modern small medium shopping malls are mostly an effort to follow the mega malls which may not be accurate from the perspective of scientific measurement. Thus, this study has attempted to understand the current practice before taking a further step prior to estimating a scientific measurement. It has also taken the initiative to analyze the gaps so that, absences can be filled with new recommendations.

Different literature suggested different concepts, analysis and theories regarding the betterment of a shopping mall and practices of facility layout. It is crucial for a shopping mall layout to consider the factors that improve the available facility with optimization of utilization. Sometimes available facilities are under-utilized, in this scenario what and how to improve the utilization to maximize the profit is utmost important. This study has explored new factors for the purpose of decision making on the basis of a case analysis undertaken on a small-medium level shopping mall in Kuala Lumpur, Malaysia and analyzed the ins and outs of the shopping mall so that, proper recommendations can be provided based on the findings. Ultimately, this research is to implement the facility layout decision model into a customized way so that, it contributes to the equation of profit maximization through precise utilization of the facility available in small and medium shopping malls. Following the pattern of big and mega malls would not bring much profit if small and medium size malls do not provide customized facilities for easing the shopping experience of their respective audience. This research has considered only those factors that were important for understanding the gap from the case analysis perspective and literature review.

\section{Research Methodology}

This research has been conducted by case analysis method, which is a big channel of qualitative method for findings. Taking the layout for each floor, this study has assessed each business as per the following tabulated form. Management of shopping mall should upkeep this information to modernize the facility layout decision model. The following table assesses a business in terms of nature, location, volume, economic and liquidity.

Table 1: A business in Terms of Nature, Location, Volume, Economic and Liquidity

\begin{tabular}{|l|c|c|c|}
\hline Particulars & Majority & Average & Minor \\
\hline Business Nature & $\mathrm{Xx}$ & $\mathrm{Xx}$ & $\mathrm{xx}$ \\
\hline Product Nature & $\mathrm{Xx}$ & $\mathrm{Xx}$ & $\mathrm{xx}$ \\
\hline Location of the center & $\mathrm{Xx}$ & $\mathrm{Xx}$ & $\mathrm{xx}$ \\
\hline Volume of Transaction & $\mathrm{Xx}$ & $\mathrm{Xx}$ & $\mathrm{xx}$ \\
\hline Stability into the Economy & $\mathrm{Xx}$ & $\mathrm{Xx}$ & $\mathrm{xx}$ \\
\hline Liquidity of the business & $\mathrm{Xx}$ & $\mathrm{Xx}$ & $\mathrm{xx}$ \\
\hline
\end{tabular}


This analysis is also different from seasonal businesses have been considered to provide competent facility layout model for upcoming competitive industry of smallmedium shopping mall. Under case analysis method, this study has observed one smallmedium shopping mall named "ABC Complex Sdn Bhd" which is situated in Malaysia. Based on publicly available amenities and the shopping mall design, this study has done critical analysis on the facilities of the case study shopping mall. Case analysis research gives much closer observation to a particular incident or sample taken for research. It discards generalization rather specification gets upheld to understand the ins and outs of the case which gives better findings than generalization. This research has derived findings from floor to floor analysis with "ABC Complex Sdn Bhd". In any research, better findings that cover every detail can find out the existing gap, which needs to be filled. Based on these gaps, researchers can provide precise recommendation in any research. A precise analysis on case (the shopping mall) for this study has found floor to floor wise difficulties for both the customer as well as traders. Later, this study has emphasized on these findings to promulgate recommended models to be implemented in the future.

\section{Background of the Case Study Organization}

$\mathrm{ABC}$ shopping mall has established and operating their business for almost 30 years in Malaysia. This establishment is very popular and well-established area to derive a good number of customers due to the density of people. The shopping has 124 shops under 28 categories of businesses. All these shops are running the business in smooth manner with warm cooperation of $\mathrm{ABC}$ Management. The total spacing on which the operation of layout planning is going on is in total 197,554 SFT (Square Feet); among which 52,513 SFT is for base and subbasement, 21,435 SFT for ground floor, 23,636 SFT for first floor, 25,944 SFT for second floor, 26,289 SFT for third floor 25,774 for fourth floor and 21,963 SFT for Fifth floor. Management office of complex is at level three operating simultaneously with the other management offices.

\section{Existing Trade Mix in the Shopping Mall}

$\mathrm{ABC}$ is a shopping mall, which has different individual businesses operating in the same environment without depending on each other. The layout by the nature of trade has a crucial effect to attract customers as well as sustain a healthy business. To analyze the current layout of "ABC Shopping Mall" the following map has been utilized. It provides a brief layout of the various floors of the mall.

Table 2: Brief Layout of the Various Floors of the Mall

\begin{tabular}{|l|l|}
\hline Ground & $\begin{array}{l}\text { Ladies Fashion/ Jeweleries/ Handphone \&accessories/ Optical/Forex } \\
\text { Exchange/ Photos/Shoes/Personal Care/Fast Food Restaurant }\end{array}$ \\
\hline First & $\begin{array}{l}\text { Ladies Fashion/ Sports Wear/Men's Shoes/Lingerie/Accessories/Cargo } \\
\text { Services/Hair Saloon/Optical/ Hand Phone Accessories/ Leather \& Bags } \\
\text { Products/ Music Shop/ Cosmetic }\end{array}$ \\
\hline Second & $\begin{array}{l}\text { Unisex Apparels/Silver Accessories/ Bags/Sports Shops/ Hair Saloon/ } \\
\text { Beauty Saloon }\end{array}$ \\
\hline Third & $\begin{array}{l}\text { Beauty center/ Fashion/ Electrical products/Silver accessories/ Bag\& } \\
\text { Luggage/Specialty/Stockiest/Internet/Beauty Academy/Services }\end{array}$ \\
\hline Fourth & Family entertainment center/Internet/Video Games/ Karaoke Box \\
\hline Fifth & Food Court/Snooker Centre/Family entertainment Centre \\
\hline
\end{tabular}




\section{Analysis on ABC Complex Sdn. Bhd.}

From the overall physical observation and examination of documents related to the layout of $\mathrm{ABC}$ shopping mall, the following general observations are derived.

The mall is performing sound in Malaysia. This shopping mall is well planned to accumulate the business and by the variety of nature at the same time. If the mall settles the same nature of trade in one particular space in a specific floor then, it would facilitate customers to enjoy shopping within an efficient duration of time. Lately, the growth of shopping mall is significant in an economy like Malaysia, where majority of the youth likes to spend their leisure time. So, in such an environment, marketing and promotion can be more effective through the creation of a layout that eases the shopping experience of customers inside the shopping mall. When frequently buying products like food and beverage, the food court should be at lower floor as the probability of customer switching is higher for such businesses.

There are certain trades that require security and the products are also highly demanded by customers. In such cases, these types of businesses should be placed on upper floor, like banking, jewelry, ATM services etc. As per statement of the management, all the businesses are ensured that they feel secure in their existing position. This is a proactive measure for assuring security which is superior to the reactive measure. This measure can reduce the amount of premium by lowering the risk to the actuaries by improved facility layout decision considering the riskiness of the business. Intensity of competition is another significant aspect that influences the sensitivity of customers. If the supply of same nature of product is higher in comparison to the density of the population in a particular area then, the sensitivity of customer is also high in maximizing profit for the traders. Minimum level of discomfort will persuade customers to switch to other traders of the same product. Considering these factors, the management should increase the occupancy inside their layout based on the trade of similar type of business.

\section{Findings on Gaps}

Ground floor is the place where customer frequency is high and customer switch to competitors more frequently. Businesses are scattered without being sorted as similar businesses are located on one floor.

First Floor: Ladies Fashion/ Sports Wear /Men's Shoes/Lingerie/Accessories/Cargo Services/Hair Saloon/Optical/ Hand Phone Accessories/ Leather \& Bags Products/ Music Shop/ Cosmetic. Businesses like hair saloons need to be on lower floor as it is very frequently needed by customers.

Second Floor: Unisex Apparels/Silver Accessories/ Bags/Sports Shops/ Hair Saloon/ Beauty Saloon

Third Floor: Beauty center/ Fashion/ Electrical products/Silver accessories/ Bag\& Luggage/Specialty/ Stockiest/Internet/Beauty Academy/Services

Fourth Floor: Family entertainment center/ Internet/ Video Games/ Karaoke Box

Fifth Floor: Food Court/ Snooker Centre/Family entertainment Centre 


\section{Recommendation of the study}

Analyzing the gap, this study has structured an equation to calculate the priority weight that determines the specific type of trade that should be placed at a particular floor-

$$
\pi=\Sigma \alpha+\Sigma \beta+\Sigma \gamma
$$

Here, $\alpha$ represents the priority by the frequency of customer inflow in the particular outlet of trade.

$$
\begin{aligned}
& 1,2,3 \ldots \ldots \ldots \ldots \ldots \ldots \ldots . n=\text { individual outlet of same trade. } \\
& \Sigma \alpha=\alpha_{1} x \varphi+\alpha_{2} x \varphi+\alpha_{3} x \varphi \ldots \ldots \ldots \ldots \ldots \ldots \ldots+\alpha_{n} x \\
& \text { Again, } \alpha=\text { Frequency of customer } \\
& \text { Total number of customer for whole duration } \\
& \alpha=\frac{\frac{\text { Number of years operating }}{\text { Total amount of revenue }}}{\text { Number of product sold for relevant years }}
\end{aligned}
$$

To count the average size of transaction for particular trade, it is given weight multiplied with the frequency at equation no 1 , therefore;

If average $<$ RM 100 then $\varphi=.10$

If average $=$ RM 101-500 then $\varphi=.20$

If average $=$ RM 501-1000 then $\varphi=.40$

If average $=$ RM 1001-5000 then $\varphi=.80$

If average $>$ RM5000 then $\varphi=1$

Second step is to consider the security requirement by the value of transaction, which is represented by $\beta$.

$$
\begin{aligned}
& \sum \beta=\beta_{1}+\beta_{2}+\beta_{3}+\cdots \ldots \ldots \ldots \ldots \ldots \ldots \ldots \ldots \ldots \ldots+\beta_{n} \\
& \beta=\frac{\text { Minimum size of loosing one product }}{\frac{\text { Number of lost product during the whole business period }}{\text { Number of years operating }}} x \\
& \text { Average transaction size }
\end{aligned}
$$

In this equation, the factor of security required for a business has been considered to place them by lowest to highest security score at down level to upper level of the shopping mall. Average transaction value is also vital to measure the security requirements for specific nature of business. Number of lost products indicates the existing security facility in that particular area where the shopping mall is situated. These factors must be included to make optimal decision making under facility model of the shopping mall.

Third step is to consider sensitivity of customers in relation to competitors, which is represented by $\gamma$,

$$
\gamma=\frac{\text { Number of shop or trader by same nature operating into state or district }}{\text { Density of Population in particular or street }+ \text { frequency of the tourists. }}
$$

Now putting the value of equation (1), (2), \& (3) into $\pi$, we can calculate the score to decide upon which business is to place at what floor to customize the facility layout for the customer of particular district, state or area.

Decision Mode- The following steps are to be considered while implementing this facility layout decision model into practice. 
Step-1 Higher the value of $\sum \alpha$ the shop or the trade of business should be at the lower floor to facilitate the customers. As lowest weight indicates the transaction size is small thus, needs to be placed at lowest floor, customers may switch easily for similar product that the specific business can provide.

Step-2 Higher the value of $\sum \beta$ the shop or the trade of business should be at the middle to upper floor of the mall. Higher the security required, upper the placement of the business.

Step-3 Higher the value of $\sum \gamma$ the shop or particular nature of trade should be located from $1^{\text {st }}$ to lower middle floor of the shopping mall. Higher the competitor intensity, better outlet availability is required for customers.

Step-4. Rest of the business would be based on the value of $\pi$ calculated above, considering all the fact of transaction weight, security required and customer intensity.

\section{Conclusion and Implications}

Nowadays, in the continuous flow of research and development, facts and incidents are substantially being controlled by scientific logic and methodology. In operation management, most of the work and method of decision-making regarding layout has been performed on manufacturing factory and general office layout. Even though certain work has been done on high level mathematical equation, it is impossible to utilize them in terms of the design decisions required from an architectural point of view rather than business profitability, sensitivity of customer and risk assumption for loss. In this study, an attempt has been made to consider all aspects in simpler form as it can be practiced and implemented by shopping malls in sustaining and developing their position in the upcoming intensely competitive retail industry. This study has recommended some guidelines for arranging the facilities of the shopping mall in a way that can attract more customers and tourists for higher sales and frequent visits.

This study will have some implications that can direct the stakeholders for taking initiative in modifying the facility layout of existing shopping malls, and it will also direct for future set up of new shopping mall. Effective practice of facility layout decision model will enhance the shopping mall management as well as increase the sales and revenue.

\section{Research Limitations and Directions for Future Research}

To know about existing facility layout decision model in different shopping malls, this study initially approached five different shopping mall authorities in Malaysia. However, only one has given formal consent to do observation and investigation of their premises inside the shopping mall. Thus, the study findings in this research is based on one case study organization, which is not enough for generalizing and getting into a conclusion. Due to time constraints and lack of accessibility, other available organization was not possible to include in this study. The study is only conducted from Malaysian perspective, but more study can be done from cross-national comparison with other neighboring countries and also across the world. More shopping malls can be included next time to come up with more concrete findings in this area. This study can also be extended with quantitative research survey to know about behavioral aspect of research. 


\section{References}

Ahmed, Z. U., Ghingold, M., \& Dahari, Z. (2007). Malaysian shopping mall behavior: an exploratory study. Asia Pacific Journal of Marketing and Logistics. 19(4). 331348. https://doi.org/10.1108/13555850710827841

Behera, M. P., \& Mishra, V. (2017). Impact of store location and layout on consumer purchase behavior in organized retail. Anvesha, 10(1), 10-21.

Can, G. F., Kurtulmusoglu, F. B., \& Atalay, K. D. (2016). A case study on shopping malls attributes for young consumers. Young Consumers. 17(3), 274-292, https://doi.org/10.1108/YC-04-2016-00596

Chae, J., \& Regan, A. C. (2016). Layout design problems with heterogeneous area constraints. Computers \& Industrial Engineering, 102, 198-207.

Chotipanich, S., \& Issarasak, S. (2017). A study of facility management operation strategy in shopping malls: Insights from 4 top-class shopping malls in Bangkok. Property Management. 35(3), 236-253. https://doi.org/10.1108/PM-07-2015-0029

Dębek, M. (2015). What drives shopping mall attractiveness?. Polish Journal of Applied Psychology, 13(1), 67-118.

Fahmy, S. A., Alablani, B. A., \& Abdelmaguid, T. F. (2014, December). Shopping center design using a facility layout assignment approach. In 2014 9th International Conference on Informatics and Systems (pp. ORDS-1). IEEE.

Gopalakrishnan, B., Turuvekere, R., \& Gupta, D. P. (2004). Computer integrated facilities $\begin{array}{lll}\text { planning and } & \text { design. Facilities. } & 22(7 / 8),\end{array}$ https://doi.org/10.1108/02632770410547561

Jain, S., \& Yadav, T. K. (2017). Systematic layout planning: A review of improvement in approach to pulse processing mills. International Research Journal of Engineering and Technology (IRJET), 4(5), 503-7.

Kahraman, C., \& Otay, İ. (Eds.). (2019). Fuzzy multi-criteria decision-making using neutrosophic sets (Vol. 16, pp. 382-394). Berlin, Germany: Springer.

Kusiak, A., \& Heragu, S. S. (1987). The facility layout problem. European Journal of operational research, 29(3), 229-251.

Martineck, T. (2002). Facility Profile. Medical Center Takes Its Cue From the Community. Upper Chesapeake Medical Center, Bel Air, Md. Health facilities management, 15(8), 12-13.

Mowrey, C. H., Parikh, P. J., \& Gue, K. R. (2018). A model to optimize rack layout in a retail store. European Journal of Operational Research, 271(3), 1100-1112.

Pope, J. A., Lane, W. R., \& Stein, J. (2020). A multiple-attribute decision model for retail store location. Southern Business Review, 37(2), 15-25.

Roth, A. E. (2008). What have we learned from market design? Innovations: Technology, Governance, Globalization, 3(1), 119-147.

Suhardi, B., Juwita, E., \& Astuti, R. D. (2019). Facility layout improvement in sewing department with Systematic Layout planning and ergonomics approach. Cogent Engineering, 6(1), 1597412.

Zeng, S., Chen, S. M., \& Fan, K. Y. (2020). Interval-valued intuitionistic fuzzy multiple attribute decision making based on nonlinear programming methodology and TOPSIS method. Information Sciences, 506, 424-442.

Zhu, T., Balakrishnan, J., \& Cheng, C. H. (2018). Recent advances in dynamic facility layout research. INFOR: Information Systems and Operational Research, 56(4), 428-456. 